It is hard at this date to write anything new on the subject of elementary geometry, and for the class addressed by the author it is not desirable, but the wellknown facts may be treated in very diverse ways: in this case there is a novelty and freshness which must commend the treatment of them to all intelligent students. Take this "precise definition" of a plane: Take two points $A$ and $B$ and suppose two equal spherical bubbles formed about $A$ and $B$ as centres. Let them expand, always equal to each other, until they meet, and still keep on expanding. The line where the equal spherical bubbles, regarded as surfaces, meet, has all its points just as far from $A$ as from $B$. As the bubbles still expand, this line, with all its points equidistant from $A$ and $B$, itself expands and traces out a plane as its path through space. Hence we may define the plane as the region (or surface) where a point may be, that is, equidistant from two fixed points. . . It is evident that the plane, as thus defined, is reversible. . . The superiority of this definition consists in its not only telling what surface the plane is, but also making clear that there actually is such a surface. Thence our author readily derives the notion of the ray (anglicè, straight line : a tract being a part bounded by end-points).

This manner of illustration occurs repeatedly, and adds, we think, much to the interest of the book.

As a specimen of the mode of proof employed we take what is equivalent to part of Euc. i. 5. Data. ABC, an isosceles triangle, $A B$ its base, $A C$ and $B C$ its equal sides (here we may remark the figure is badly drawn: a similar remark applies to figures on $\mathrm{pp}$. 6o and 9r). Proof. Take up the triangle $\mathrm{ABC}$, turn it over, and replace it in the position BCA. Then the two triangles $\mathrm{ACB}$ and $\mathrm{BCA}$ have the equal vertical angles, $\mathrm{C}$ and $\mathrm{C}$, also the side $\mathrm{AC}=\mathrm{BC}$ (why ?) and $\mathrm{BC}=\mathrm{AC}$ (why?); hence they are congruent (why?), and the $\angle A=\angle B$.

In the more elaborate proofs there is a larger crop of "whys," and in some cases the interrogation is answered by the author.

The amount of ground covered is considerable, and yet, as we have gone through the whole of the text, it is so clearly opened up that the intelligent student, to whom we have previously referred, should be able to master it all, and successfully grapple with the well-chosen exercises which are arranged in fitting places throughout the book. "These exercises have been chosen with especial reference not so much to their merely disciplinary as to their didactic value, the author being persuaded that quite as good exercise may be found in going somewhither as in walking round the square."

We have no hesitation in heartily commending Prof. Smith's introduction to teachers and pupils as an excellent one, and this we vouch, adapting the language of the learned counsel cited by Bailie Littlejohn, nostro periculo.

Primer of Horticulture. By J. Wright. (London: Macmillan and Co., I 893.)

THIS primer contains the substance of ten lectures delivered by Mr. Wright for the Surrey County Council. Besides the lectures, some sets of questions, asked after the lectures, are given together with the answers to these questions.

The primer is eminently practical, and is sure to prove very useful both to gardeners and to students. It cannot, however, be considered quite free from errors, and a careful revision would increase its value.

Sometimes the text is rather loose.

On p. 54 the word pistil is used indefinitely, sometimes meaning the style and at others the whole gynoecium.

Speaking of phosphatic manures on p. 64 the author says :-

"Mineral superphosphate is ground coprolite treated with sulphuric acid.

"Coprolite is antediluvian petrified manure, of which NO. 1223 , VOL. 47 ? there are large beds in the Eastern Counties. It is fairly active, yet sustaining.

"Thomas's phosphate powder, or basic slag-... is composed of $\mathrm{I} 5$ to 25 per cent. of phosphoric acid and about 45 per cent. of lime. It is not very quick in action, but lasting in effect."

From this description one cannot get much idea of the relative values of these three phosphatic manures, and basic slag suffers by comparison with ground coprolite. Practical experience shows that basic slag has a much higher value than ground coprolite as a manure, and has, moreover, an additional value as a check upon wireworm.

Again, on p. 77 , the description of the fungus causing potato disease (phytophthora infestans) is scarcely accurate. In describing the aerial hyphæ which spring from the mycelium in the leaves and push their way through the stomata, the author says :-

"These stem-growths of the fungus produce 'fruit'spores (DD) in cells (Oogonia), that divide (F) and liberate the active agents in reproduction, tailed zoospores (G) which float in the air, and swim in the moisture, dew, or rain, on potato leaves." The letters in parentheses refer to fig. 18, p. 79. Neither text nor description below fig. I 8 is correct. What Mr. Wright calls oogonia are really conidia, and what he calls conidia ( $\mathrm{F}$ in fig. 18 ) represent the formation of an oospore from oogonium and antheridium. We must also dissent from the author's views on zoospores floating in the air.

Apart from these defects the primer is well worthy of perusal, and will no doubt meet with success. The practical part is very well done, and this is, of course, the most essential part of the book. WALTER THORP.

\section{Ornithology in relation to Agriculture and Horticulture.} Edited by John Watson. 220 pp. (London: W. H. Allen, I893.)

THIS book contains a series of papers by well-known writers. The chief interest will gather around chapters iii. to vii. inclusive, which treat of the common sparrow. The trial of the sparrow is opened very ably by Mr. Chas. Whitehead (for the prosecution). He is well supported in the next chapter by Miss Eleanor A. Ormerod. These two writers for the prosecution will have the support of the vast majority of agriculturists in England, and their arguments contrast favourably with the less practical defence put forward in the two succeeding chapters by the Rev. F. C. Morris and the Rev. Theodore Wood.

Chapter VII. is written by J. H. Gurney, Jun., and from the result of 755 dissections he draws up a table showing that "in England about 75 per cent. of an adult sparrow's food is corn, chiefly barley and wheat, with a fair quan tity of oats." Nobody with experience of grain-growing in England will deny that the sparrow is a terrible pest, and it is time that a movement be made not towards exterminating the troublesome bird, but towards reducing its numbers to normal limits.

Chapter IX. is an interesting defence of the rook, much of which defence this bird merits. It is written by O. V.Aplin, who also contributes a very useful chapter on miscellaneous small birds. WALTER THORP.

\section{LETTERS TO THE EDITOR.}

[The Editor does not hold himself responsible for opinions ex. pressed by his correspondents. Neither can he undertake to return, or to correspond with the woriters of, rejected manuscripts intended for this or any other part of NATURE. No notice is taken of anonymous communications.]

Vectors versus Quaternions.

HAVING a vivid recollection of the pleasure I derived from Prof. Gibbs's attacks upon the quaternionic system in the rather one-sided discussion that took place about two years ago in this 